\title{
De twee culturen
}

\section{WeSSEL KRUL}

Een nieuwe wereld heeft twee thema's. Allereerst is het boek een geschiedenis van de opbouw van de economische infrastructuur in Nederland in de tweede helft van de negentiende eeuw. Van der Woud beschrijft de introductie van de stoommachines, de spoorwegen, de aanleg van de kanalen en het wegennet, de waterhuishouding, de bruggen, de posterijen, de trambanen, de electriciteit. Hij doet dit met een aanstekelijk enthousiasme, in een kleurrijke taal en opvallende metaforen, alsof hij zelf gegrepen is door de demon van de vooruitgang en zijn lezers wil laten delen in de opwinding die de grote en onstuitbare verandering moet hebben opgewekt. Een nieuwe wereld is een overtuigende weerlegging van de nog altijd invloedrijke mythe van de Nederlandse 'Jan Salie'-geest, van de veronderstelling dat de industrialisatie en de nieuwe technologie in Nederland lange tijd slechts weinig belangstelling zouden hebben gehad en schoorvoetend, bijna met tegenzin, zouden zijn aanvaard. Van der Woud laat zien dat er na het midden van de eeuw ook in Nederland in een grote verscheidenheid aan publicaties een nieuwe pragmatische mentaliteit baanbrak, gericht op een doelmatige toepassing van de steeds omvangrijkere technische mogelijkheden, zowel in het particulier als in het algemeen belang (want daartussen werd meestal geen principieel onderscheid gemaakt). Er kwam in Nederland veel in beweging. Het wordt uit dit boek eens te meer duidelijk dat de stemming van triomf die omstreeks 1900 soms merkbaar was al een lange tijd van voorbereiding had.

Maar omstreeks 1900 werd ook de kritiek op de vooruitgang steeds luider. Die kritiek werd ingegeven door de radicale eenzijdigheid waarvan het nieuwe pragmatisme getuigde. Alles wat zich niet liet weergeven in termen van nut en voordeel, van verbetering en standaardisering, dreigde in het proces van vernieuwing onverschillig terzijde te worden geschoven. Het ging om een bekend soort klachten, die gewoonlijk werden (en worden) geformuleerd als een contrast tussen wetenschap, techniek en progressie enerzijds en cultuur, bezinning en beschaving anderzijds. De nieuwe pragmatische instelling, door Van der Woud zo treffend weergegeven als het normale denken, dat wil zeggen het denken in meetbare eenheden, had weliswaar een indrukwekkende bijdrage geleverd aan het levenscomfort, maar zij gaf geen antwoord op vragen van moraal, persoonlijke verhoudingen of esthetiek. Zij leek een belangrijk deel van de kwaliteit van het leven te miskennen. De toename van het comfort schiep echter juist de ruimte om aan dit soort problemen in veel ruimere mate aandacht te schenken. In 1913, bij het eeuwfeest van de onafhankelijkheid, publiceerde C. te Lintum een veelgelezen gedenkboek dat hij Een eeuw van vooruitgang noemde. ${ }^{1}$ Hoofdstuk na hoofdstuk liet hij alle vernieuwingen de revue passeren waardoor het bestaan in Nederland in de negentiende eeuw

1 C. te Lintum, Een eeuw van vooruitgang, 1813-1913 (Zutphen 1913). Zie ook uitvoeriger: W. 
veiliger, bedrijviger, kansrijker en welvarender was geworden. De negentiende eeuw, daar bestond voor de auteur geen twijfel over, was een eeuw van triomf. En toch eindigde hij zijn boek met een moment van aarzeling. Was de aanblik van Nederland in de afgelopen eeuw ook mooier geworden? Die vraag stemde hem tot zorg, en daarom kon hij zijn terugblik toch niet helemaal in majeur afsluiten.

De verhouding tussen de technologische vooruitgang en de cultuur is het tweede onderwerp van Een nieuwe wereld. Op dit punt begint het verhaal ingewikkeld te worden. Van der Woud wil een geschiedenis geven van de materiële vooruitgang, maar tegelijkertijd wil hij laten zien hoe er over deze vooruitgang werd gedacht, wat de ideeën waren waardoor de vernieuwing werd gestimuleerd en welke reacties zij opriep. Met name de eerste helft van het boek is meer een bloemlezing van optimistische uitspraken dan een overzicht van behaalde resultaten. $\mathrm{Nu}$ behoren meningen en overtuigingen, ook wanneer zij hun zekerheid ontlenen aan positieve feiten en pragmatische overwegingen, tot de sfeer van de cultuur. Dit brengt Van der Woud ertoe om het negentiende-eeuwse geloof in verbetering, nut en vooruitgang voor te stellen als de opkomst van een nieuwe manier van denken en daarmee van een nieuw type beschaving. Deze beschaving staat in evident contrast met de historische opvatting van beschaving als 'Bildung', dat wil zeggen als een proces van morele en esthetische educatie. Om de tegenstelling toe te lichten grijpt Van der Woud terug op de cultuurkritiek van Ortega y Gasset, Jaspers en Huizinga.

Op het eerste gezicht is het nogal raadselachtig wat deze auteurs in een boek over de technologische transformatie van Nederland tussen 1850 en 1900 te zoeken hebben. Hun veelbesproken cultuurkritische publicaties dateren uit de jaren 1930. Zij vertolken de zorgen en stemmingen van een heel ander tijdperk. Maar er bestaat een artikel dat kan verklaren waarom Van der Woud hen in deze context opvoert. Zoals bekend, beschouwde Huizinga de mechanisering als een bedreiging van de ware cultuur. De klassieke openingszinnen van zijn Schadwwen van morgen uit 1935 laten daar geen twijfel aan bestaan.

Wij leven in een bezeten wereld. En wij weten het. Het zou voor niemand onverwacht komen, als de waanzin eensklaps uitbrak in een razernij, waaruit deze arme Europese mensheid achterbleef in verstomping en verdwazing, de motoren nog draaiende en de vlaggen nog wapperende, maar de geest geweken. ${ }^{2}$

Krul, 'Vooruitgang en verlies. Het moeizame begin van de Nederlandse monumentenzorg', De Negentiende Eeuw 29:1 (2005) 3-21, aldaar 3-5.

2 J. Huizinga, In de schaduwen van morgen. Een diagnose van het geestelijk lijden van onzen tijd [1935], in: Idem, Verzamelde Werken VII (Haarlem 1950) 313-428, aldaar 315. 
Machinekamer van de gemeentelijke Elektriciteitscentrale (Collectie Gemeentearchief Rotterdam, catalogusnummer XV 188.01.01.03-19)

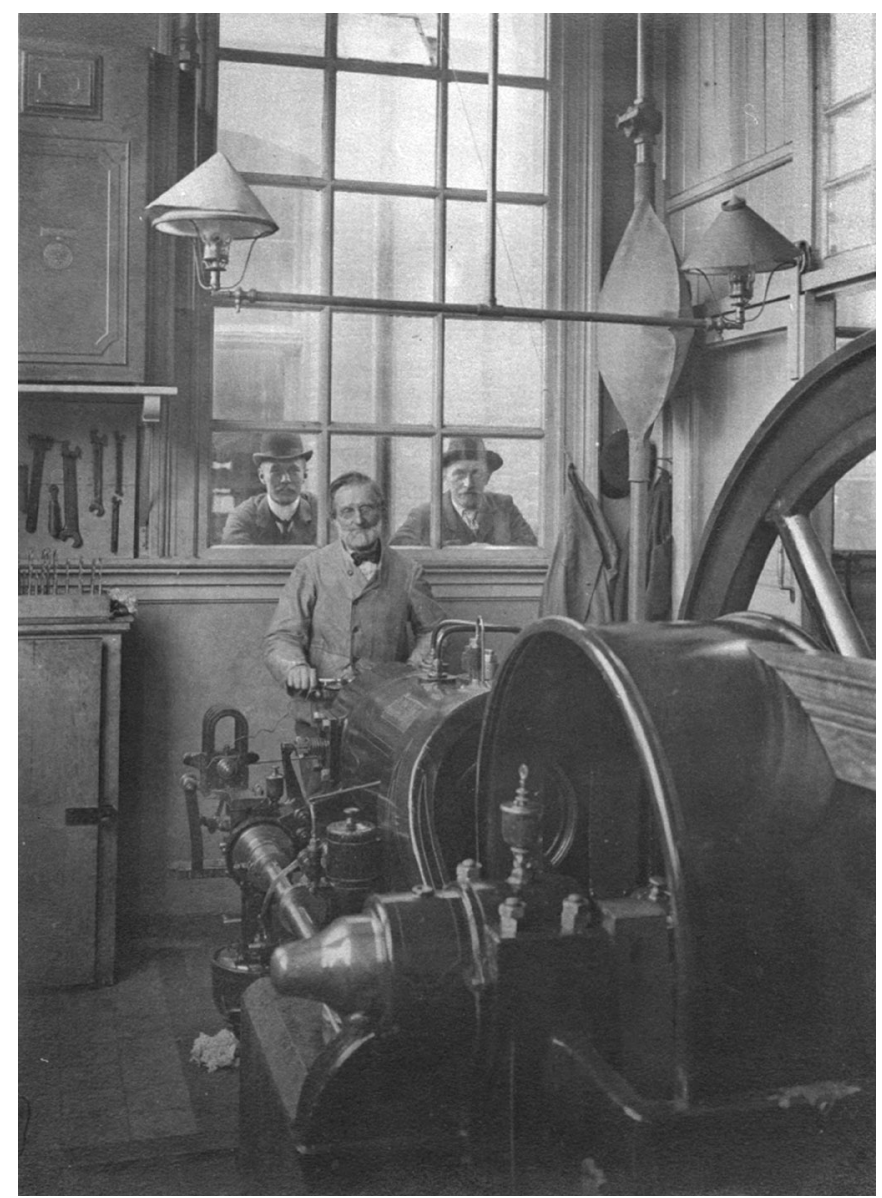

In een voordracht uit 1967 heeft W.F. Hermans zich afgevraagd hoe de wereld er uit zou zien als het omgekeerde het geval was: 'als op een goede dag de geest er nog wel was, maar de motoren niet meer draaiden, geen enkele meer, nergens meer'. De mechanische en technologische vooruitgang, meende Hermans, is de enige werkelijke vooruitgang die in de geschiedenis kan worden vastgesteld. Onder historici wil dit feit echter maar niet doordringen. Tot hun schade. 'Het is het ongeluk van de meeste historici en beoefenaars van geesteswetenschappen, dat zij daar zo weinig gevoelig voor zijn. Techniek is niet in staat hun eerbied, of zelfs maar hun romantische geestdrift op te wekken'. ${ }^{3}$

De naam van W.F. Hermans komt in Een nieuwe wereld niet voor, maar het lijkt erop dat Van der Woud er op uit is geweest om als historicus nu

3 Willem Frederik Hermans, 'Kan de tijd tekens geven?' [1967], in: Idem, Van Wittgenstein tot Weinreb. Het sadistische universum 2 (Amsterdam 1970) 86-109, aldaar 105, 109. 
eindelijk aan zijn wensen tegemoet te komen, met inbegrip van de romantische geestdrift. Dat is lovenswaardig. Maar Van der Woud wil zijn bevindingen een plaats geven in de traditionele cultuurgeschiedenis. Of liever misschien, hij wil uit zijn onderzoek een nieuw cultuurbegrip afleiden. Als gevolg van deze doelstelling bevat Een nieuwe wereld drie opvattingen van cultuur. Ten eerste lijkt Van der Woud soms te suggereren dat de vooruitgang in de techniek zelf de kern van de cultuur is, of in ieder geval een zo essentiële voorwaarde dat al het overige daarvan afhankelijk is en in vergelijking daarmee onbelangrijk wordt. Zonder de door Huizinga zo beklaagde groei van verkeer en vervoer, transport en communicatie, zou er nauwelijks cultuur kunnen bestaan. Ten tweede wil Van der Woud het geloof in de verlossende werking van de techniek en de mentaliteit die daarmee samenhangt, het pragmatisme en het 'normaaldenken', als een nieuwe vorm van cultuur definiëren. En ten derde is er de oude cultuur, die zich tegen het vooruitgangsdenken keerde en die in Huizinga en sommige tijdgenoten zeer welbespraakte zegslieden vond.

De situatie wordt verder gecompliceerd door de ambivalentie die Van der Woud tegenover de verschillende culturen aan de dag legt. Uit zijn erkenning van de betekenis van de techniek volgt onvermijdelijk dat hij het bijbehorende geloof in vooruitgang, pragmatisme en zakelijke probleemoplossing moet aanvaarden als de meest wenselijke cultuurvorm. Soms lijkt hij dat ook te doen. Maar hij is zich tegelijkertijd bewust van de beperkingen van deze houding, van de nietsontziende dadendrang en zucht naar financieel voordeel die er steeds mee samen zijn gegaan. De nieuwe cultuur van de vooruitgang was inderdaad vaak hetgeen door talloze cultuurcritici is betreurd als 'materialisme'. Ook Van der Woud kan niet aan deze conclusie ontkomen.

Dat verkeer en handel, wetenschap en techniek noodzakelijke voorwaarden zijn voor de bloei van de beschaving, is al een oude wijsheid. Zonder dat, zegt Thomas Hobbes in boek XIII van zijn Leviathan uit 1651, is het leven 'nasty, brutish and short'. Hier is weinig tegen in te brengen. Maar is het daarom nodig de naïeve lyriek op de vooruitgang bij te vallen die Van der Woud op bladzijden 104 en 112 van Een nieuwe wereld aanhaalt? In 1863 bekroonde een commissie uit de Koninklijke Akademie van Wetenschappen een in het Latijn gesteld vers 'De vapore', ofwel 'Over den stoomketel'. De dankbare dichter, een Italiaan overigens, verklaarde daarop van plan te zijn in een uitgebreid Latijnsch gedicht in vier boeken den Stoom in den ruimsten omvang te behandelen'. Het is misschien maar goed dat het er niet van is gekomen. ${ }^{4}$ Zelfs als we inzien dat er zonder techniek weinig cultuur kan bestaan, is de techniek maar zelden een inspirerend onderwerp voor het traditionele soort van cultuuruitingen.

Daar is een eenvoudige reden voor, die trouwens door W.F. Hermans in het aangehaalde essay ook wordt genoemd. Techniek is op zichzelf waardevrij. De techniek bepaalt zelf niet op welke manier zij wordt toegepast. $\mathrm{Zij}$ is in moreel opzicht neutraal. Dit is het grote misverstand van Huizinga en veel van zijn

4 Wessel Krul, 'De Koninklijke Akademie en de geesteswetenschappen, 1855-1865', in: K. van Berkel (ed.), Het oude Institunt en de nieuwe Akademie. Overheid en wetenschapsbeoefening omtrent het midden van de negentiende eeuw (Amsterdam 2000) 91-162, aldaar 146-148. 
tijdgenoten. $\mathrm{Zij}$ meenden dat bepaalde technische vernieuwingen een mentaliteit in het leven riepen die vijandig was aan wat zij als cultuur beschouwden. Hun gedachtegang was niet onbegrijpelijk. Op het enthousiasme van de vernieuwing, het blijde vooruitgangsgeloof en het vertrouwen in de oplosbaarheid van de grote maatschappelijke problemen dat Van der Woud beschrijft, volgde in 1914 de catastrofe van de Wereldoorlog. Alles wat tot dan toe was uitgevonden en ingezet tot heil van een zo groot mogelijk aantal mensen bleek ook te kunnen worden gebruikt in dienst van een ongekende massaslachting. De les die Huizinga, Ortega en vele anderen uit de oorlog trokken is dat de techniek werkt als de machten die de tovenaarsleerling uit de ballade van Goethe heeft opgeroepen. 'Die ich rief, die Geister, werd ich nun nicht los'. Eerst lijken de nieuwe vindingen nuttig en worden zij verwelkomd, maar op den duur ontwikkelen zij een eigen dynamiek. Zij groeien de mensheid boven het hoofd, en dwingen deze tenslotte, onstuitbaar en onomkeerbaar, een rampzalige kant op. In 1935, toen Huizinga schreef, was het duidelijk dat er een nieuwe wereldoorlog op komst was, zo mogelijk nog verschrikkelijker dan de voorgaande.

Maar was dat allemaal de schuld van de techniek zelf? Wat Van der Woud bindt aan Huizinga is dat ook hij de techniek als een cultuur wil beschouwen, dus als een domein waarin morele en politieke beslissingen worden genomen. Er zijn goede argumenten om dat niet te doen. De techniek oordeelt niet over consequenties. De cultuur doet dat wel. Het is daarom beter om techniek en cultuur als twee gescheiden sferen te blijven beschouwen. Dezelfde techniek kan voor de meest uiteenlopende doelen worden ingezet. Het is de cultuur die beslist over de verhouding van deze doelen en hun relatieve waarde. Daarom kan een geschiedenis van de techniek nooit samenvallen met een geschiedenis van de cultuur. Van der Woud heeft een meeslepend boek geschreven over de nieuwe technologieën van de negentiende eeuw en de toepassing daarvan in de Nederland. Maar als cultuurgeschiedenis geeft Een niewwe wereld inderdaad niet meer dan voorwaarden en grondslagen. Het boek eindigt abrupt. Nergens wordt aangegeven dat dit een eerste deel is, maar de vorm doet vermoeden dat er nog een tweede helft komt waarin de knoop die hier is ontstaan misschien weer wordt ontward.

Wessel Krul (1950) is hoogleraar moderne cultuurgeschiedenis aan de Rijskuniversiteit Groningen.

\section{Summary}

Wessel Krul, Two Different Cultures

In his Een nieuwe wereld (2006), Auke van der Woud charts the rise of a new technological culture in the second half of the 19th century. He contrasts the optimism shown by the writers of this period with the pessimism which pervaded thinking on culture in the earlier part of the 20th century. In this commentary it is argued that technology is not a separate sphere of culture but that it is value-neutral, inducing optimism or pessimism according to the use made of it. 


\section{Repliek}

\section{AUKE VAN DER WOUD}

Het is een eer dat mijn boek door vier collega's zo serieus wordt besproken, ik zal proberen sommige van hun punten te verhelderen. De beschouwing van Anton Schuurman nodigt echter vooral tot tegenspraak uit. Ik kreeg het gevoel dat hij meer behoefte aan explicitering heeft dan het boek biedt. Ik hou van tussen de regels door lezen, van de cello in een kamerorkest, de drum en de bas in een band, van figuranten op het toneel, van de achtergrond die vaak onopgemerkt voor de structuur, en ook voor de diepte in de klank en de kleur zorgt. Is dat de belangstelling en zijn dat de middelen waar Schuurman op doelt waar hij schrijft dat ik de lezer meer wil verleiden dan overtuigen? Er is iets in de aanpak van Schuurman dat me de indruk geeft dat hij zich met hand en tand tegen verleiding verzet. Hij heeft vrij veel bezwaren tegen zaken die niet in het boek staan (zoals zijn foute interpretatie van Nietzsche's 'God is dood' die hij mij verwijt) en tegen het ontbreken van onderwerpen die juist wèl in het boek staan. Hij wil ook een ander type boek. Hij heeft een wetenschappelijke boodschappenlijst, ik was op zoek naar een partituur. Hij wil een formeel kader, overzichten van nationale en internationale literatuur, hij wil zien hoe ik mij verhoud tot schrijvers die hij en ik hoogachten en dringt erop aan dat ik de overbekende verhalen over de relatie tussen de Verlichting en de negentiende eeuw, en over de trekvaarten van Jan de Vries, nog eens navertel. Ik was echter niet zo bezig met conventionele kaders maar zocht naar een nieuwe constructie die het verleden met het hier en nu verbond, een nieuwe geschiedenis waarin ook bekende thema's zouden worden opgenomen en er wat nieuwer uit zouden gaan zien, zoals de urbanisatie, de dynamiek van het kapitalisme, de democratisering, de staats- en natievorming, het beschavingsoffensief en het ontstaan van de Nederlandse spoorwegen. Het belangrijkste was niet eens de verzameling van die thema's, maar het nieuwe construct, het verhaal over een zeer herkenbaar verlangen in de negentiende eeuw, in dit geval naar meer communicatie en mobiliteit dan ooit voorstelbaar was geweest, en over de wil om de mogelijkheden daarvoor te realiseren. Welke wetenschappelijke boeken moet men lezen om iets heel nieuws te maken? Ik realiseer me dat ik met deze onvoorzichtige vraag en het nog roekelozere antwoord de Icarus van de Nederlandse geschiedschrijvers zal worden en door de goden spoedig in zee kan worden gedumpt. Ik heb namelijk niet heel veel aan wetenschappelijke voorbeelden gehad en beken maar eerlijk dat ik de meeste inspiratie uit de krant kreeg, uit berichten over de explosieve toename van het sms-verkeer en de collaps van de 'oude' communicatiemedia in een of twee jaar, en door om me heen te kijken: de gezichtsexpressies te lezen die bij het mobiel bellen ontstaan, de automobilisten in hun vastberaden gretigheid te bespieden als ze mij aan het inhalen waren, en oude mensen in de tram waar te nemen, in hun stille waardigheid die bij hun oude voorbije wereld hoorde. Als ik al wetenschappers zou willen verleiden, 